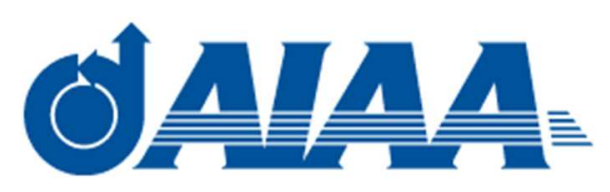

\title{
A Value Based Decision Environment: Vision and Application
}

\begin{tabular}{|r|l|}
\hline Journal: & Journal of Aircraft \\
\hline Manuscript ID: & $2012-10-$ C032153.R1 \\
\hline Manuscript Type: & Full Paper \\
\hline Date Submitted by the Author: & n/a \\
\hline Complete List of Authors: & $\begin{array}{l}\text { Gorissen, Dirk } \\
\text { quaranta, erika; university of southampton, Aeronautics, Astronautics and } \\
\text { Computational Engineering } \\
\text { Ferraro, Mario; university of southampton, Aeronautics, Astronautics and } \\
\text { Computational Engineering } \\
\text { Schumann, Benjamin; university of southampton, Aeronautics, } \\
\text { Astronautics and Computational Engineering } \\
\text { Van Schaik, Jeroen; university of southampton, Aeronautics, Astronautics } \\
\text { and Computational Engineering } \\
\text { Bolinches I Gisbert, Marc; university of southampton, Aeronautics, } \\
\text { Astronautics and Computational Engineering } \\
\text { Keane, Andy; university of southampton, Aeronautics, Astronautics and } \\
\text { Computational Engineering } \\
\text { Scanlan, Jim; university of southampton, Aeronautics, Astronautics and } \\
\text { Computational Engineering }\end{array}$ \\
\hline Subject Index Category: & $\begin{array}{l}\text { 40710 Multidisciplinary Design Optimization < 40000 INTERDISCIPLINARY } \\
\text { TOPICS, O3410 Uninhabited and Unmanned Air Vehicles < 00000 } \\
\text { AIRCRAFT TECHNOLOGY, CONVENTIONAL, STOL/VTOL, 12800 Distributed } \\
\text { Systems and Networking < 12000 COMPUTING, INFORMATION, AND } \\
\text { COMMUNICATION }\end{array}$ \\
\hline
\end{tabular}




\title{
A Value Based Decision Environment:
}

\section{Vision and Application}

\author{
D. Gorissen ${ }^{1}$, Erika Quaranta ${ }^{2}$, Mario Ferraro ${ }^{3}$, Ben Schumann ${ }^{4}$, \\ Jeroen van Schaik ${ }^{5}$, Marc Bolinches I Gisbert ${ }^{6}$, Andy Keane ${ }^{7}$, and Jim Scanlan ${ }^{8}$ \\ University of Southampton, University Road 1, SO17 1BJ, Southampton, UK
}

The ever increasing complexity and environmental constraints associated with aerospace and defense projects are putting pressure on traditional organizational structures for design decision making. No longer can the design problem be assimilated and steered by a single chief engineer. Rather, in order to find consensus, design involves a complex iterative process between the different specialist committees (weights, aerodynamics, structures, cost, etc.). Furthermore, there is a growing need to take into account the life cycle implications of low level design decisions in addition to their more direct implications on performance. The Decision Environment for Complex Designs (DECODE) project at the University of Southampton aims to explore how the design process may be streamlined under these circumstances. The case study presented here centers around a maritime surveillance UAV for search and rescue tasks, developed in association with the UK Coastguard. The focus is on "value driven" design and how advances in software engineering, rationale capture, operational simulation, and rapid prototyping can be leveraged to create an integrated design suite that allows the rapid design and manufacture of low cost civilian UAVs.

\footnotetext{
1 Research Fellow, Computational Engineering and Design Group, dirk.gorissen@soton.ac.uk, AIAA Member

2 Research Fellow, Computational Engineering and Design Group

3 Graduate Research Assistant, Computational Engineering and Design Group

${ }^{4}$ Graduate Research Assistant, Institute for Complex Systems Simulation \& Computational Engineering and Design Group

5 Graduate Research Assistant, Computational Engineering and Design Group

6 Graduate Research Assistant, Computational Engineering and Design Group, AIAA Member

7 Professor, Computational Engineering and Design Group

8 Professor, Computational Engineering and Design Group, AIAA Member
} 


\section{Introduction}

As in many areas, product complexity in the Aerospace and Defense (A\&D) sector has been continuously increasing, some would argue at a greater rate than the accompanying organizational decision making process, which has had to evolve as a result. The current value of an aerospace prime contract is now typically measured in billions, yet perhaps surprisingly, many aerospace and defense companies still use relatively traditional processes and design tools within their programs [1]. It is uncommon to find tightly integrated tool chains and the more complex the designs being considered the less likely this becomes. In the past, and during each stage of design, a chief engineer would assimilate information from a number of disciplines and use experience, intuition and judgment to make top-down decisions in seeking good trade-offs. A good example of this was Kelly Johnson, renowned for his work on many aircraft designs, including the U2 and SR-71 [2].

Today, the sheer scale, breadth and increasing complexity of A\&D systems no longer permits the design problem to be assimilated by a single individual. Hence the chief engineer role is now largely associated with managing committees of specialists to review and sanction consensus driven/devolved decisions at very large and lengthy design review meetings. The quality of the outcome of these design review meetings crucially depends on the clarity, currency, parity and impartiality of the information presented. Gathering and vetting this information is in itself a challenging undertaking and the presentation thereof at design review meetings typically takes the form of a series of presentations and/or spreadsheet based calculations, grouped by domain of subsystem. The static nature of these presentations means that, even with good quality information, decision makers (i.e., a chief engineer) still heavily rely on judgment and intuition to make trade-off decisions.

Consequently, the authors see two related opportunities here. The first is a need to extend existing design review capabilities to encompass the life-cycle dimension. Here the interest of the authors lies in the application of Value Driven Design (VDD) [3]. Value-based design approaches involve the creation of a model that captures all the attributes important to the stakeholders and translates them into a single measure of value. This value metric is then used to guide the designer toward the best possible system. The main advantage of a value-based design process over traditional approaches lies in the systematic and simultaneous evaluation of cost and benefits of 
design alternatives [4]. In traditional cost-centric and requirement-based engineering, the system is optimized to achieve a minimum life-cycle cost while meeting a desired performance level or, inversely, the best performance given a maximum program cost. Instead, in VDD, a large flexibility in the system requirements and cost is allowed in order to explore a larger part of the design space and detect the most valuable solutions [5]. This enables the engineers and the customers to make performance, cost and time trades at the performance definition phase, reducing the risk of costs and time overrun.

Secondly, the authors also see an opportunity for active design environments where trade-offs can be examined by teams of senior engineers able to ask probing questions of "live" models in short timescales and at variable fidelity levels. Without them, designers are currently unable to easily understand or rationally exploit the relationships between performance, cost and life. Suitable active systems should, moreover, inherently automate the process of generating review information leaving specialist staff with more time to provide broader and more complete domain models supported by improved data sets.

\section{A. Vision}

These observations led to the instigation of the DECODE project at the University of Southampton, UK. The aim is to investigate design decision support tools that provide holistic optimization at a system level so as to maximize satisfaction of all the stakeholders associated with the system. Unusually, the DECODE tool suite aims to provide active design exploration of systems level tradeoffs between performance, unit costs and system life-cycle costs based on a "design mission control capability". The goal is to integrate early concept design exploration with full resolution, geometry backed, design analysis, detailed manufacturing and operations models; all interlinked through the storage of associated data, knowledge and experience accumulated during the design process.

Designers will be able to use the system to review, trade-off and manipulate a design in real time, spawning detailed aerodynamic, structural, costing and econometric calculations at will, using cloud based technologies to run simulations, while at the same time interpolating over pre-computed results using response surface based capabilities. This mixture of live computations, data-mining 
over existing results and high quality display systems lies at the heart of the (ambitious) vision proposed here.

It is worth emphasizing that despite all the advances that have been made in computational analysis the fundamental hallmark of design is not analysis but synthesis. The choice of appropriate mechanism types, power sources, the setting of dimensions, the choice of features and subcomponents, the selection of materials and manufacturing processes - all these are acts of synthesis and it is the skillful making of decisions in these areas that is the hallmark of the good designer. Of course designers use analysis all the time, but design is about decision making and analysis is, by contrast, an act of gaining understating not of making decisions. Moreover, to be a good designer the most often cited personal prerequisite is experience - this view is backed up by many observational studies in engineering design offices [6, 7]. So, even though design decision making is commonly preceded by a great deal of information gathering and analysis, and although the gathering of such information, often using computational models, may be a very skilled and time consuming activity, it should be made clear that whatever the cost, this remains just a precursor to the decisions that lie at the heart of design. From the point of view of the system this means paying attention to the capture and integration of design rationale, as well as the integration of mission simulation models. The former providing a qualitative and the latter a quantitative basis for the decision making process.

\section{B. Research context}

The challenged faced by DECODE is well summarized by Price et. al. in [8]:

However, the whole life cycle modelling of an aircraft within the context of systems engineering [...] is at an infant stage as the integration is highly complex involving additionally people, product and processes which do not fit easily with engineering analyses. The major challenge is to provide this environment such that technical details can be accounted for appropriately, without overwhelming the high level design challenges and where the influence of data and parameters throughout and across systems is clearly understood. 
These fundamental problems are not new and have been the subject of research for some time, both in our own group [9] and by others. For example, the various projects related to Problem Solving Environments $[10,11]$ come to mind, as does the extensive work by MIT's Strategic Engineering group on Multidisciplinary Design Optimization [12], Systems Architecture and Engineering [13], and System Lifecycle Properties [14]. The University of Buffalo has developed a novel design space representation technique known as the Hyper-Radial Visualization Method [15] for exploring Pareto solutions in a high dimensional performance space and demonstrated an innovative trade space exploration of satellite datasets using a "Design by Shopping" paradigm. Penn State University has developed a virtual design environment to allow simulation based design as well as virtual exploration of design trade-offs for the complex design space of an engineering product [16].

There has also been much interest in enabling whole aircraft simulation and multidisciplinary analysis early on in the design stage [17-21], particularly on Unmanned Aerial Vehicles (UAVs) [22-25]. Typically each reference presents a framework for implementing and solving the Multidisciplinary Design Optimization (MDO) problem. Most are custom built (e.g., [26]) with some based on existing tools (e.g., Modelcenter in [23]) and some fully open source (e.g., [27]). Well known tools in this category include VSP [28] and CEASIOM/CPACS [29, 30]. A very good and extensive overview of these topics and the wider domain of systems engineering is given by Price, Raghunathan and Curran in [8].

Our work is complementary to these efforts as it takes a value driven design view on decision making. A strong emphasis is placed on integrating design rationale, mission simulation and value modules while trying to leverage existing frameworks (e.g., for the multidisciplinary analysis) where possible. In addition the complete design-manufacture-flight test cycle is excercised multiple times throughout the project in order to gain a full understanding of the impact design decisions have.

Value-driven design is a movement that is using economic theory to transform systems engineering to better use optimization to improve the design of large systems, particularly in aerospace and defense $[3,31]$. One example is the work in [32] where a value-centric design methodology is used to compare monolithic and fractionated spacecraft. This is an area that has also been recognized by the AIAA as a key priority. The AIAA has sponsored the creation of a program committee entitled 
"Value Driven Design" [33] to stimulate research in this area. The DECODE team are represented on this committee which is very strongly supported by US and UK based industry including Boeing, NASA, Rolls-Royce, Lockheed Martin, QinetiQ, Pratt \& Whitney, Cessna, Raytheon and others. The remainder of the paper will give a high level overview of the different topics \& problems covered in the DECODE project and the current status (the project is still ongoing). Given the breadth of tools and disciplines that come together, this paper cannot go into each in detail. Topics not covered in depth here will be covered in separate publications. For example the operational simulation is already covered in [34-36].

\section{Use case}

This work centers around a primary use case: the design of a small, 10-20 hour endurance, medium range $(\approx 1000 \mathrm{~km})$, low speed $(\approx 25 \mathrm{~m} / \mathrm{s})$, maritime reconnaissance UAV which operates changeable but essentially pre-planned missions. The aim has been to keep the maximum dry weight below $20 \mathrm{~kg}$ to take advantage of the reduced certification requirements that are thus applicable. Each year of the project involves going through the full design cycle, from concept design to flight testing, necessary to fully appreciate the full reach of a design decision.

Although by industry standards this is a relatively simple system it is sufficiently complex to present severe research challenges in optimizing a system level design against performance, unit cost and life-cycle cost targets. An example of one of the design variations being considered is that of a morphing wing [37] versus a conventional wing. The aim being to see if a radical technology can justify itself when all aspects of a design, including operational, through-life and fleet mix issues are considered.

Instead of the traditional iterative spiral, DECODE adopts a more agile design process. The preliminary design phase is not separated from the concept stage - all design variables are considered to lie in the concept phase unless they live only within the CAD based definition process, in which case they are considered detailed design variables. Similarly, considerations of manufacturing methods are not separated from the detailed design work - rather they are closely integrated so that the designs take maximum advantage from the manufacturing systems employed. In service 
maintenance and decommissioning are considered as part of the mission simulation and are thus considered from the outset.

\section{DECODE Modules}

The DECODE project has been built around the use of a series of integrated design environments that have at their hearts parametric geometry representations linked to appropriate display systems, analysis tools and databases. These draw on the existing toolsets available to the authors, supplemented by a small set of new tools considered necessary to deliver on the vision. The different modules that make up the DECODE environment are shown in figure 1.

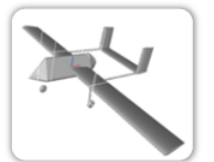

Concept Design

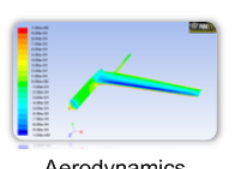

Aerodynamics

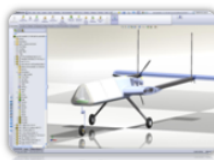

CAD

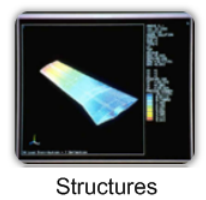

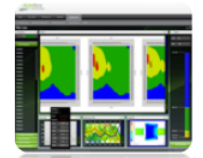

Design Viewer

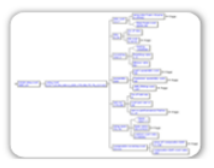

Costing

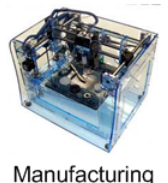

Manufacturing

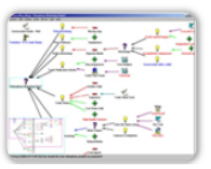

Design Rationale
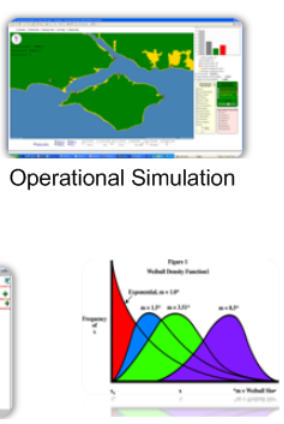

Reliability
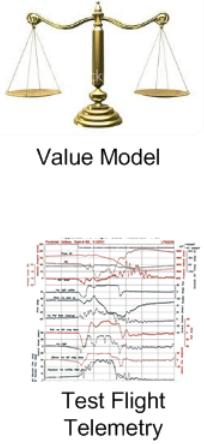

Fig. 1: DECODE modules

The environment that ties the modules together is built around a traditional N-tier architecture, consisting of three tiers or layers: a data management layer, a logic or orchestration layer, and a presentation layer (see Fig. 2). So far the majority of the work has concentrated on the orchestration and presentation layers with a basic, but functional implementation for the data layer.

\section{A. Design modules}

Central to the DECODE design process is the concept design tool which was developed from basic principles [38, 39] and augmented with empirical data coming from previous UAVs designed and built in our group. This was implemented in a formally structured spreadsheet as well as in the commercial Pacelab ${ }^{T M}$ suite programming environment in order to evaluate the merit of a more free form approach versus a more structured and formal one. The concept model has two geometry generation backends. The first backend publishes into the Solidworks ${ }^{\top M}$ CAD package to obtain 


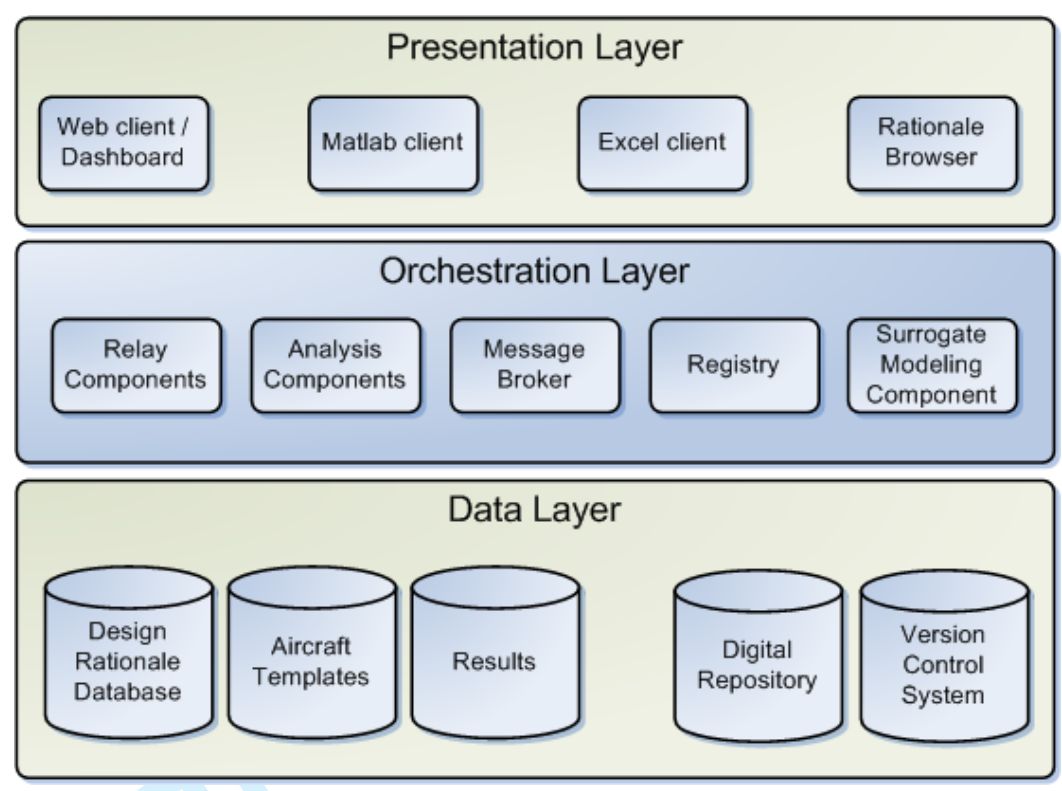

Fig. 2: Three-tier systems architecture

the geometry used as a basis for detailed design. The second backend publishes into ANSYS ${ }^{\mathrm{TM}}$ Workbench which is used to perform aeroelastic analysis and CFD analysis using Fluent ${ }^{T M}$. There is also the option of using the analysis geometry as the basis for the detailed CAD model. A lower fidelity full potential code with viscous corrections is available as well [40] which is used when the accuracy requirements are more relaxed. Both ANSYS and Abaqus ${ }^{\mathrm{TM}}$ FEA are used for structural analysis (which is particularly important for the morphing wings) and a custom flight data capture module is used to easily extract information from auto pilot telemetry data coming from test flights.

Note also the addition of an explicit manufacturing module. In DECODE the detailed design work is closely integrated with the manufacturing methods used, in this case rapid prototyping methods such as Selective Laser Sintering, laser cutting, and digital foam cutting. This allows for a rapid turnaround time for new ideas and allows one to quickly test out concepts at a relatively low cost. Additionally, using $3 \mathrm{D}$ printing means a designer has more design flexibility as considerable geometric complexity can be added at little or no manufacturing cost. The same flexibility holds for the aerodynamic shape as well. 


\section{B. Design evaluation modules}

1. Mission simulation

Using concept design and CAD tools, and steered by analysis codes, a design team is able to come to an air-worthy design, ready for manufacture. Mission planning provides the context where all this activity comes together, the raison d'être for the design process being started in the first place. It provides the operating boundary conditions, determining the requirements on key performance parameters such as range, endurance, altitude, and payload weight while taking into account expected weather conditions and take-off and landing provisions. In addition the mission requirements provide a baseline benchmark against which the value of a particular aircraft configuration or design feature can be tested. In DECODE the agent-based discrete-event simulation environment Anylogic ${ }^{\mathrm{TM}}$ has been used to construct a model of the Lee-on-Solent area on the South coast of the UK [34, 41] (Fig. 3). The scenario simulated is where a fleet of UAVs join helicopters and the lifeboats in Search and Rescue (SAR) missions in the English Channel. Data is derived from the Royal National Lifeguard Institution and the Maritime and Coastguard Agency incident statistics whereas operational procedures are recreated from qualitative investigation. Inputs define the UAV characteristics and a reliability model while outputs give information on operational benchmarks such as fuel used, number of missions and utility.

\section{Value calculation}

The operational simulation produces results such as the "number of UAV launches", "total helicopter flight time", "Average response time", etc. The UAV performance impacts not only on the metrics directly related to the aircraft (like the UAV fuel consumption) but also on the behaviour of the other agents (e.g., the total time spent by the lifeboats on the rescue operation will be less if a better performing UAV detects the location of the accident in less time). The value calculator exploits such information in order to provide a ranking of design alternatives that takes into account mission effectiveness and life-cycle cost according to the principles of Value Driven Design.

VDD is a methodology whereby the "goodness" of a design is expressed as a single number and that this number is derived from the product definition. Hence if a designer changes any aspect 


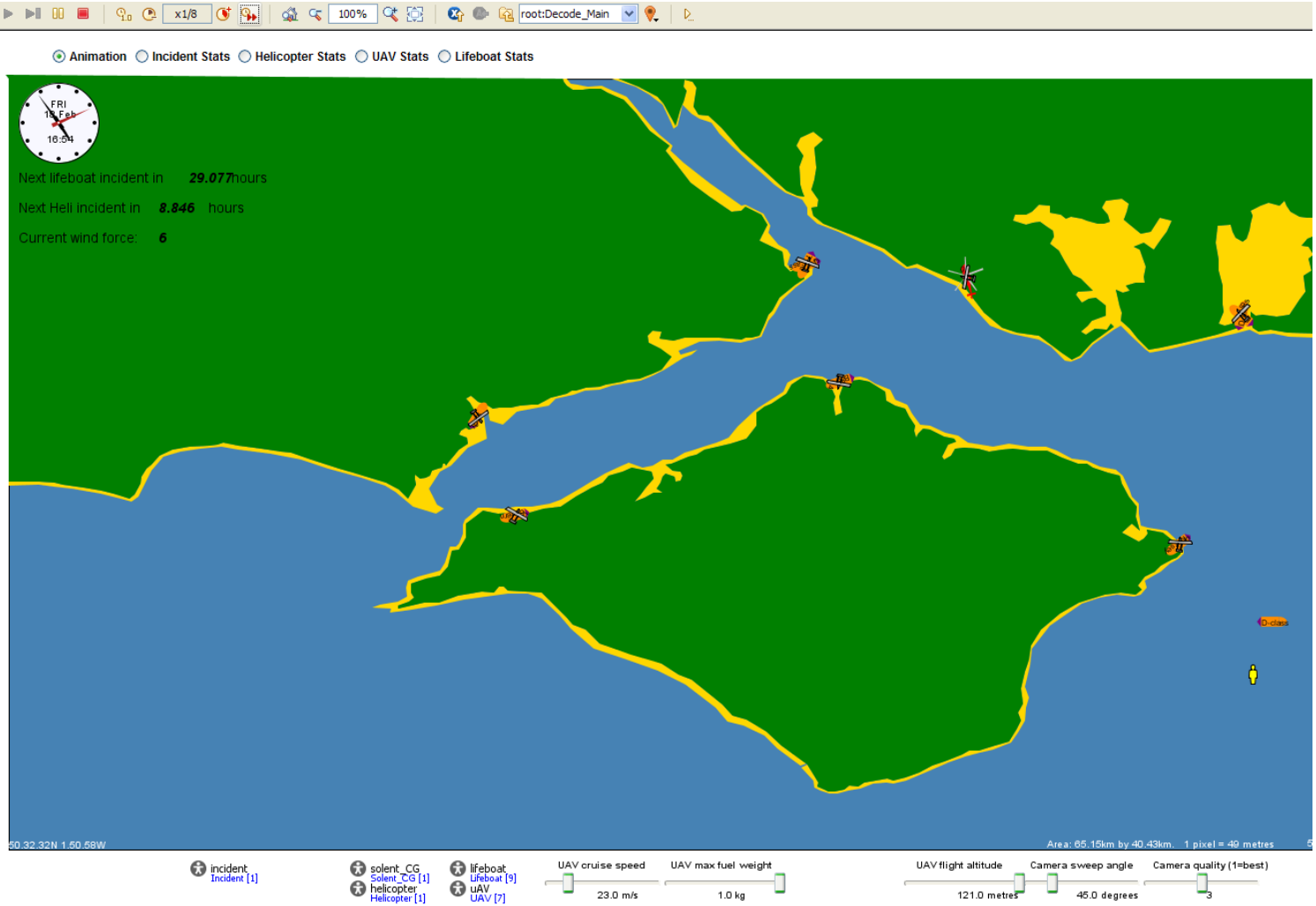

Fig. 3: The Lee-on-Solent area, with the various SAR helicopter stations, modeled in the Anylogic agent based simulation software

of the product definition then the impact on the overall change to the "goodness" of the design is calculated. In this context the product definition is a broad one and encompasses the geometries associated with the design, the materials, the manufacturing processes and the implicit performance of the design such as strength, life, capability, etc.

Conceptually this is a straightforward concept but in practice there are formidable challenges. For designs that operate in a commercial context the "Value" metric can take the form of a balance sheet whereby a "surplus value" can be calculated over a given (usually multi-year) time period. The surplus value calculates the likely income directly relating to the design and debits all the costs associated with the design. Our group has developed a number of example value models for industry sponsors such as Rolls-Royce, BAE Systems and Airbus (e.g., [42]).

A good example of a non-commercial model was developed by Thokala [43]. This work led to the development of a large collection of integrated models that allowed the effects of changes 
to the design of a UAV to be evaluated. In this case of course there is no income stream from operation of the design. This model therefore established a given capability that had to be rigorously maintained irrespective of changes to the design of the UAV. Hence the Value metric measures the cost of establishing and maintaining a fixed capability over a given (multi-year) time period. A particular complication within this model was that the UAV had to fly within hostile airspace. The model therefore had to include a sophisticated damage/attrition model as a result of ground fire and missiles. This attrition model had to correlate damage/attrition likelihood with vehicle performance parameters such as airspeed, maneuverability, radar cross section.

In DECODE the value model is implemented as a Vanguard ${ }^{T M}$ model. A full discussion of this model is out of scope for this paper, but in essence it combines information from the operational simulation (number of lives saved, number of UAVs needed, number of maintenance operations, etc.) and costing model (also a Vanguard model) to produce the final value number. More details are given in section V B.

Eventually it is likely that there will be multiple value models or that the user has direct access to the different weightings used to ensure the objective of the value model and that of the user are directly aligned.

\section{Design rationale}

Design rationale is "... the notion that design goes beyond merely accurate descriptions of artifacts, such as specifications, and articulates and represents the reasons and the reasoning processes behind the design and specification of artifacts." [44]. Such information is notoriously hard to elicit from a domain expert, partly due to the fuzzy notions of "experience" and "expert knowledge", but also in no small part due to the extra effort (and hence cost) that is required to record, manage, and update said rationale. Design rationale capture is part of a much larger field known as knowledge management or knowledge engineering. This is an area which has seen increasing research activity over recent years $[45,46]$ and encompasses the complete spectrum from knowledge elicitation from experts, to reasoning from gathered knowledge with automated reasoning software.

In DECODE the authors are primarily concerned with capturing design decision rationale, 
investigating how it is used, and being able to present and query this information on demand. Some preliminary results are discussed in [47]. To capture the rationale the open source tool Compendium [48] is used. While development on it has somewhat stagnated, it is a mature, stable tool and its open source nature makes it easy to link and interface with. Multiple users can collaborate on a shared rationale database and it is relatively straightforward to extract interesting summary statistics such as "The number of decisions without supporting evidence". Our current work is focused on integrating the rationale database with the CAD tool such that a designer can directly associate rationale with $\mathrm{CAD}$ variables, features, and assemblies. In turn this enables us to automatically identify areas of the CAD model which lack sufficient rationale and flag them for further scrutiny.

\section{Module orchestration}

The main purpose of analysis is to support synthesis, to supply a designer with supporting evidence in order to reduce the uncertainty in the decision making process. It is thus a requirement for any design rationale collection and recording process. Analysis also allows a designer to ask explorative "what-if" type questions (what if a better but heavier camera were used?) and perform design exploration and optimization. DECODE takes this one step further by integrating the mission simulation and value models. For example, while traditionally one might vary the wing span in order to optimize the aerodynamic efficiency, in DECODE the authors are additionally interested in how this change in wing span influences the number of lives that can be saved at sea with a fleet of UAVs over a period of 10 years. Thus while traditional 'computational' quantities like drag, stress, etc. remain important, the authors are ultimately more interested in the value of a particular product, process, or mission change. With value being a combination of the required performance metrics (cost, reliability, lives saved, etc.) taken over the full life-cycle of the mission. In essence the goal of DECODE is to connect the low level (propeller diameter, engine power) with the high level (fleet reliability over 10 years).

An added requirement is that analyses should be available in multiple fidelities (e.g., empirical formulae, response surface model, potential code, full Reynolds Averaged Navier Stokes solver). In the context of a design review meeting, feedback is typically expected to be quick (order of seconds) 
1

3

4

5

7

8

9

10

11

12

13

14

15

16

17

18

19

20

21

22

23

24

25

26

27

28

29

30

31

32

33

34

35

36

37

38

39

40

41

42

43

44

45

46

47

48

49

50

51

52

53

54

55

56

57

58

59

60

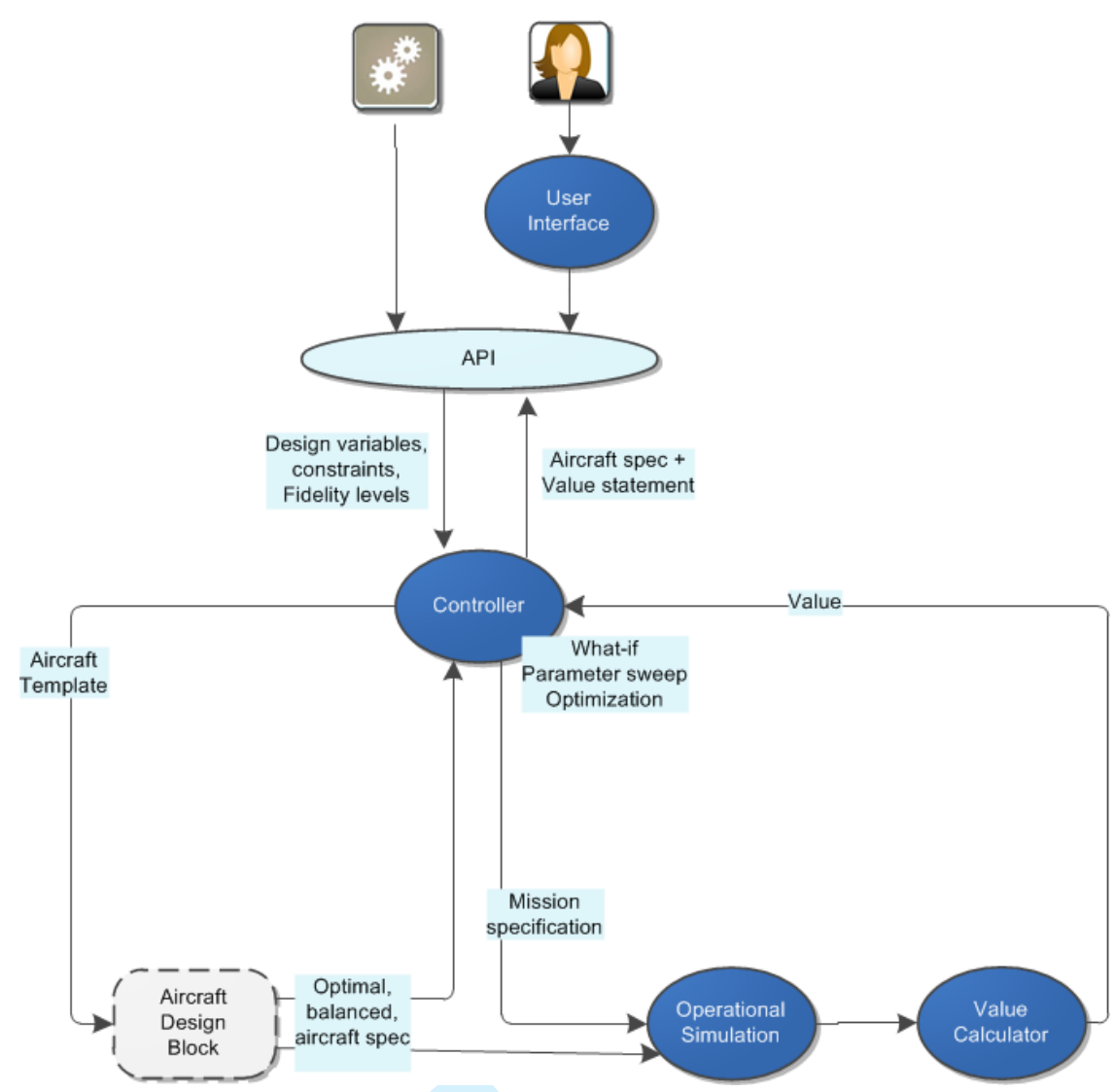

Fig. 4: The high level control flow in the DECODE system.

and accuracy requirements are less stringent. However, for important decisions an accurate analysis is required, implying that the computational chain will be longer and involve more high fidelity codes.

To enable these kinds of scenarios a software system is needed to orchestrate the different modules and perform the multidisciplinary analysis. A full discussion of this system is out of scope for this paper so only a high level overview is given here.

Figure 4 shows the top level system control flow. A client (user or program) interacts with the system through a user interface or API and has the option of executing just the left balancing loop, the right operational simulation loop (using a pre-calculated specification from the database) or both. There are currently three interfaces defined: a scriptable Matlab interface, a set of Excel functions, and a click-and-point website. These build on the three APIs that are available: Java, $\mathrm{C} \#$, and Python. Through the UI, the user drives one or more controllers, each representing one of the system use cases (e.g., parameter sweep). A controller then generates a series of aircraft 


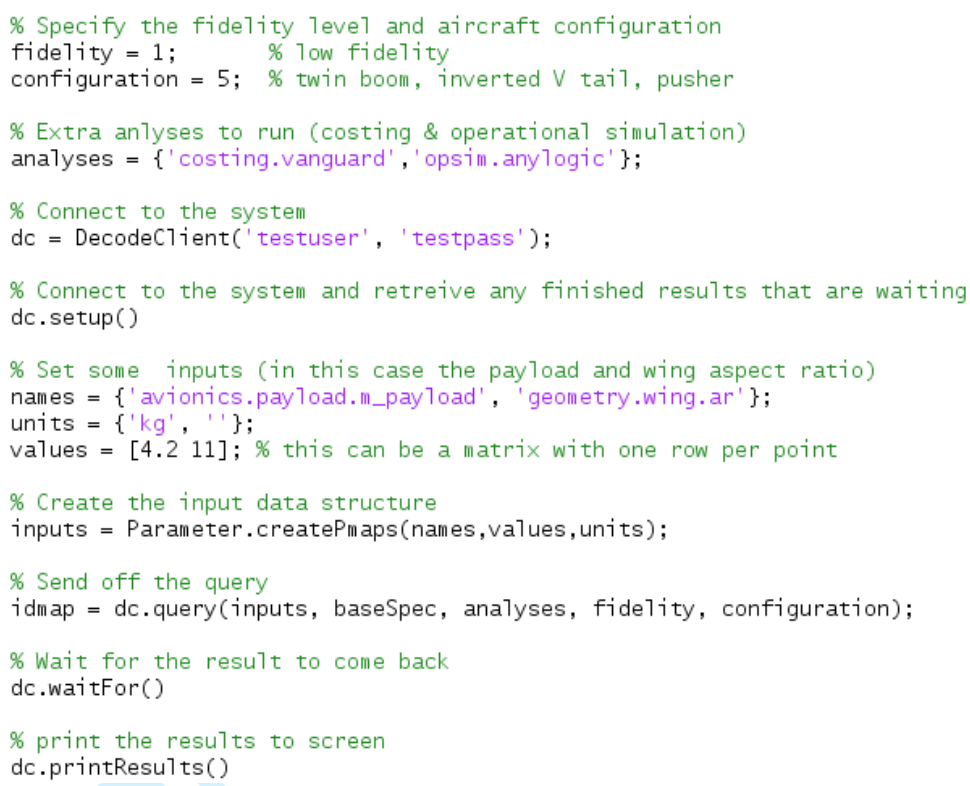

(a) Matlab client, submitting a single query.

\section{DUDE Design a UAV Check results System status About Help Sign out digrdog}

1. Describe your query

Description Enter a description for this query

2. Select a configuration

Configuration Conventional

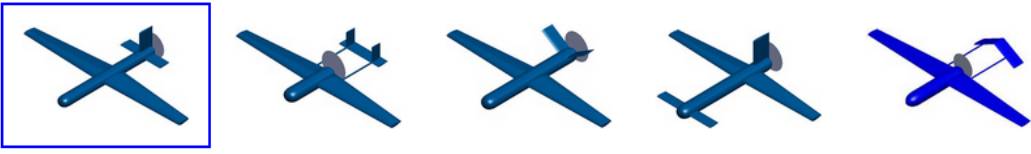

3. Choose a fidelity level

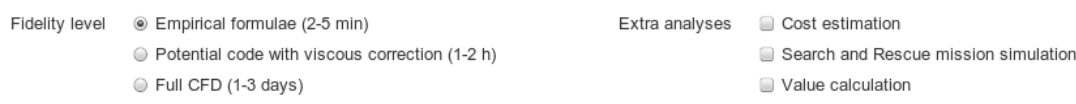

4. Specify your requirements

Search filter Type to search for a parameter by name or description

\begin{tabular}{|c|c|c|}
\hline Parameter & Description & Value \\
\hline$\checkmark$ aero.cruis & & \\
\hline & coefficient of lift at design cruise speed & 0.191 \\
\hline
\end{tabular}

(b) The web based client. The user is able to select a configuration, fidelity level, specify input parameters and download result data on completion.

Fig. 5: Screenshots of two of the clients currently available for the DECODE system. 
design templates, capturing the main design drivers and constraints, that are passed into an aircraft design block which produces an optimal (with respect to a weighted combination of the aircraft performances) aircraft. The user then has the choice of having control pass back to the controller or running the aircraft specification through the operational simulator and value model.

The aircraft design block is composed of multiple independent components (called relay, balance, and analysis components) that are responsible for performing the multidisciplinary analysis and coordinating the analysis codes. Currently an iterative relaxation scheme is used to ensure a fully balanced aircraft (i.e., lift equals weight, centre of gravity in the right place, etc.) but the authors plan to use the OpenMDAO framework [27] for this in the future.

The system was designed to be very loosely coupled, fault tolerant, and highly distributed as a collection of lightweight components/services with minimal shared state. Components communicate through messages so there is no particular dependence on any programming language or operating system. There is no limit to how many instances of a system component may be running or where they are physically located. Also a component may die at any time without impacting the rest of the system, its peers will just pick up the slack. This results in very good horizontal scalability which is necessary to do large trade studies. In concrete terms this means that the controller and balancing components may be running on local desktop machines, the analysis components distributed over one or more clusters, the operational simulation models provisioned in the cloud and the value model running on yet another desktop machine. Some demonstration code that links the availability of a certain component to the desktop screensaver, making resource scavenging possible, is also available.

\section{Results}

While some modules are still undergoing improvements, the main functionality is in place and the system has been deployed on a number of desktop machines as well as the University of Southampton Iridis (8064 cores) and Spitfire (400 cores) clusters. The system can be accessed through a Java and Matlab API or through a web application (shown in Fig 5).

Thus it already allows us to perform trade studies to analyze the impact of design choices. Figures 6 and 8 show some examples. The variables varied are the payload weight (representing a 
camera system) and landing speed. The landing speed is used because of its impact on the aircraft size and wing loading. Thus it is a good surrogate for the overall performance of the aircraft.

\section{A. Aircraft performance}

Figure 6 shows a number of surface plots related to the aircraft performance and cost (pusher configuration with a twin-boom inverted V-tail). The dry weight (Fig. 6a) of the aircraft increases by increasing the payload weight, partly because of the weight of the payload itself and partly because of the larger and heavier structural components that are thus required. The weight increase

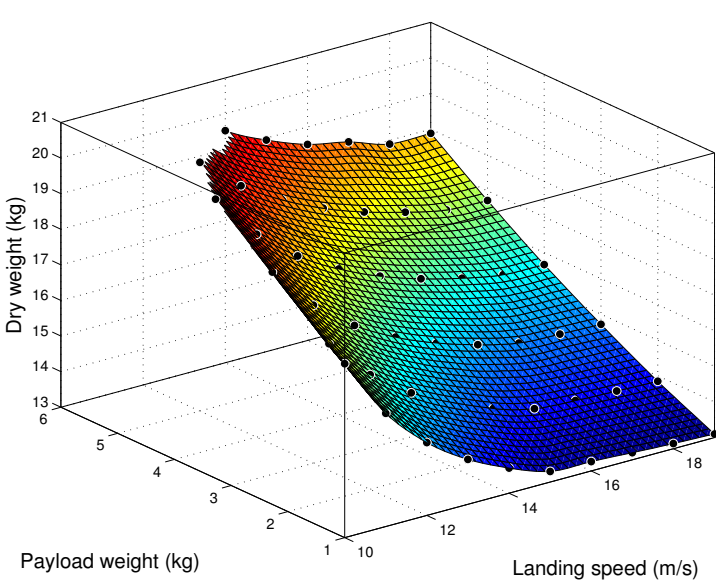

(a) Dry weight

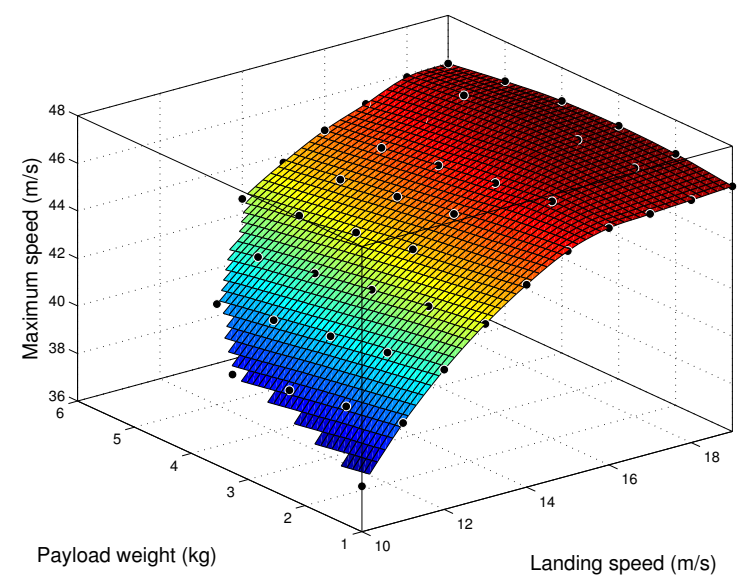

(c) Maximum speed

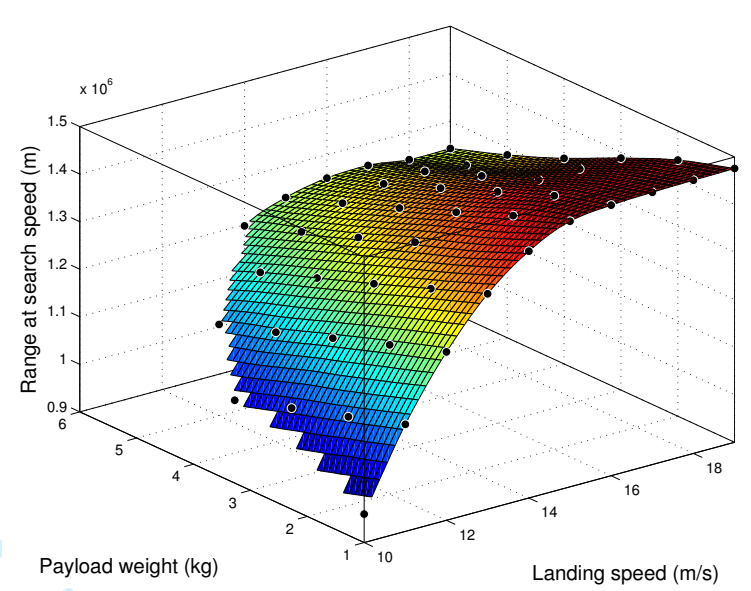

(b) Range at search speed

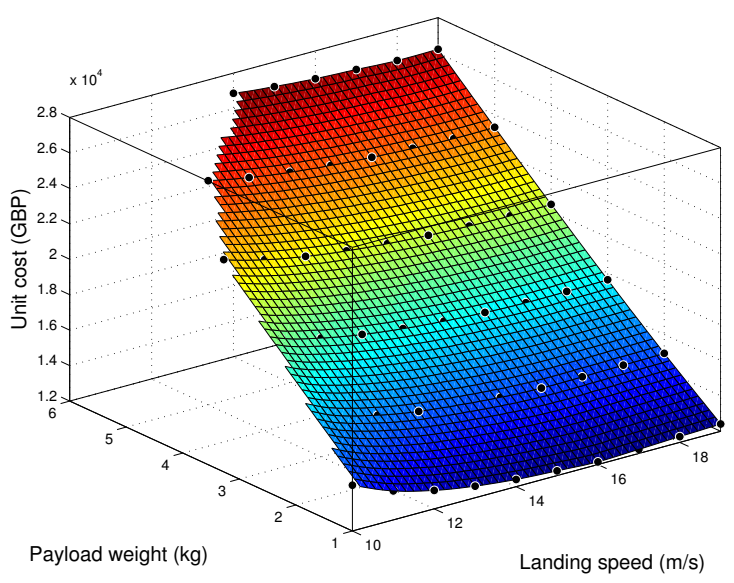

(d) Unit cost

Fig. 6: UAV design related surface plots 
has a negative impact on the aircraft performance like the range at search speed (Fig. 6b) and the maximum cruise speed of the aircraft (Fig. 6c). Figure 6d shows that the unit cost of the UAV is strongly influenced by the payload weight: the quality and cost of the recognition sensors are assumed to be proportional to weight of the payload and the payload cost represents a high portion of the total aircraft cost. The dry weight (Fig. 6a) increases by decreasing the landing speed mainly because larger wings are required. Larger wings require a larger empennage for control and stability and lead to an overall larger aircraft with higher structural weight. A larger heavier aircraft generates more aerodynamic drag and thus has a lower range and maximum speed (Fig. $6 \mathrm{~b}$ and 6c). In addition, a larger airframe is more expensive (Fig. 6d).

\section{B. Mission performance}

Integrating the operational simulation and value model then allows generating a second set of high level mission related plots. In this case the operational simulation was run for 5 years with

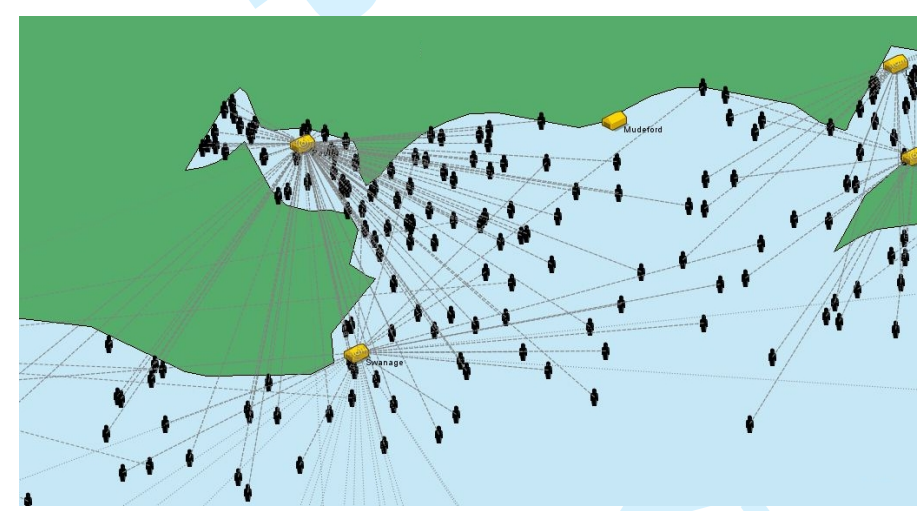

Fig. 7: Section of the South English coast showing the incident locations and coast guard stations in the operational simulation model.

incident data derived from historic information. Currently, in order to simplify the model, the mission simulation assumes that only one UAV participates to the SAR mission. When an accident occurs within its operative range, the UAV takes-off and dashes at maximum speed until it reaches the approximate location of the SOS signal. Then it starts the search phase: the UAV flies at a constant speed that allows the sensors to operate optimally. If the position of the person is identified before reaching the maximum search time, it is communicated to the closest lifeboat which then 
proceeds with the rescuing operation; otherwise the UAV aborts the mission and returns to the base to refuel and prepare for another mission. Figure 7 shows a close up of the incident distibution over a part of the South East coast of the UK.

Figure 8 shows how the mission performance and overal value of a UAV design is linked to the aircraft performance. From Fig. 8a it can be seen that increasing the payload decreases the average time needed to rescue the casualty because it is assumed that a heavier camera system is able to produce higher quality imagery and thus is able to spot incidents quicker and with a higher probability. The time to rescue reduces for UAVs with higher landing speeds because they can dash faster (Fig. 6c) and thus start searching more quickly. Figure 8b shows how the number of lives saved varies with the UAV design. Since the time in water is the primary measure for incident survival, UAVs that can spot incidents earlier (i.e., aircraft with a heavy payload and high landing speed) increase the number of saved lives. Figure $8 \mathrm{c}$ reflects the number of aircrafts purchased over the five-year period, i.e., how many UAVs crashed due to inflight failure (this is driven by a reliability model) or landing mishaps and needed to be replaced. The main driver is "crashes-duringlanding" with the probability of a crash being proportional to the kinetic energy during touch down. Therefore, a heavier UAV will have many more crashes as would a UAV with a higher landing speed.

Fixing then a particular design, Fig. 9 shows how the probability of survival varies over the mission area. When an accident occurs, lifeboats and UAVs start searching for the casualty simultaneously. If a UAV spots the accident first, it communicates its position and the closest lifeboat proceeds with the rescue operation. Generally, the accidents that are closer to a lifeboat station are more likely to be spotted by the lifeboats first, while the ones far from the coastline are most likely found by the UAVs. The quicker the accident is identified the higher the probability of survival. Generally, accidents closer to the shore have a higher probability of surviving. However, this also depends on the type of incident: an incident representing a person who has fallen ill and needs to be evacuated from a ship is very different from an incident representing a person lost at sea (the 'blue islands' in Fig. 9).

The data from these and other plots is further fed into the value model which produces a single number representing the overall value of a particular UAV design for the search and rescue mission. 


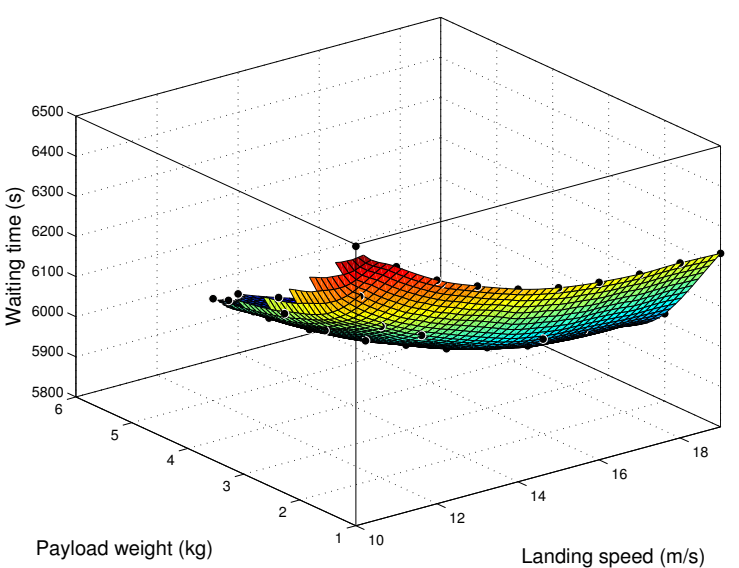

(a) Average time a casualty is waiting to be rescued

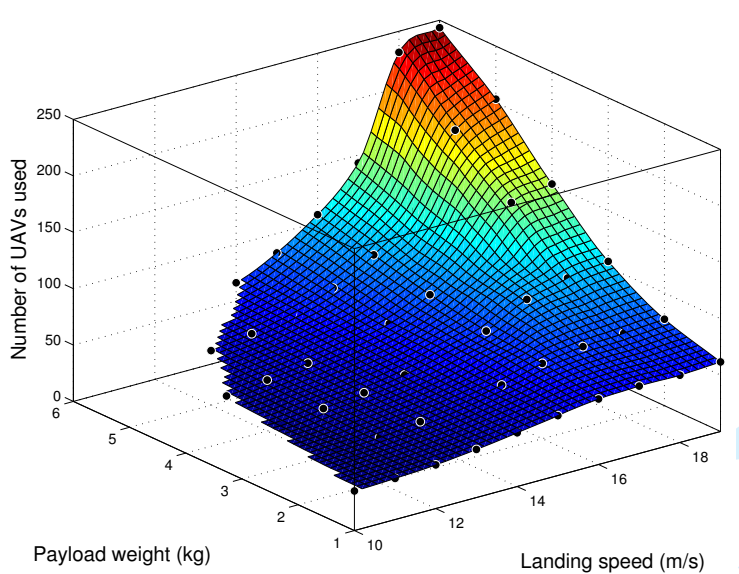

(c) Number of UAVs used

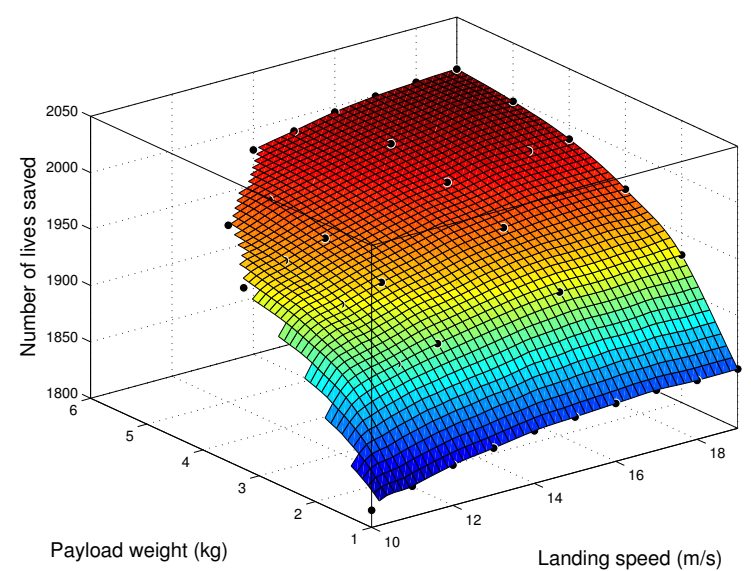

(b) Number of lives saved

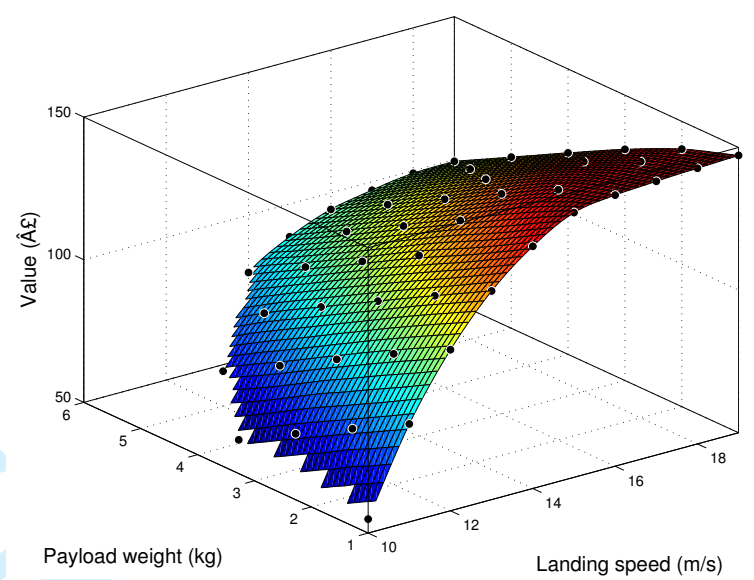

(d) Overall value number

Fig. 8: Value related surface plots

The high level structure of the value model used is shown in Fig. 10. The difference between the value of the rescue operation and the cost to perform it is the net value of the search and rescue mission. The value of the rescue mission is based on the number of lives saved and the value of a statistical life (VSL), which is the value that government agencies use to perform the cost-benefit analysis of investments in health and safety. The value added by the UAVs to the SAR operations is obtained by subtracting the baseline case in which the MCA is not equipped with UAVs. The result is illustrated by the surface plot in Fig. 8d. The VSL is assumed to be GBP 4m, according to the estimate by Viscusi and Aldy based on several worldwide market studies [49]. The plot 


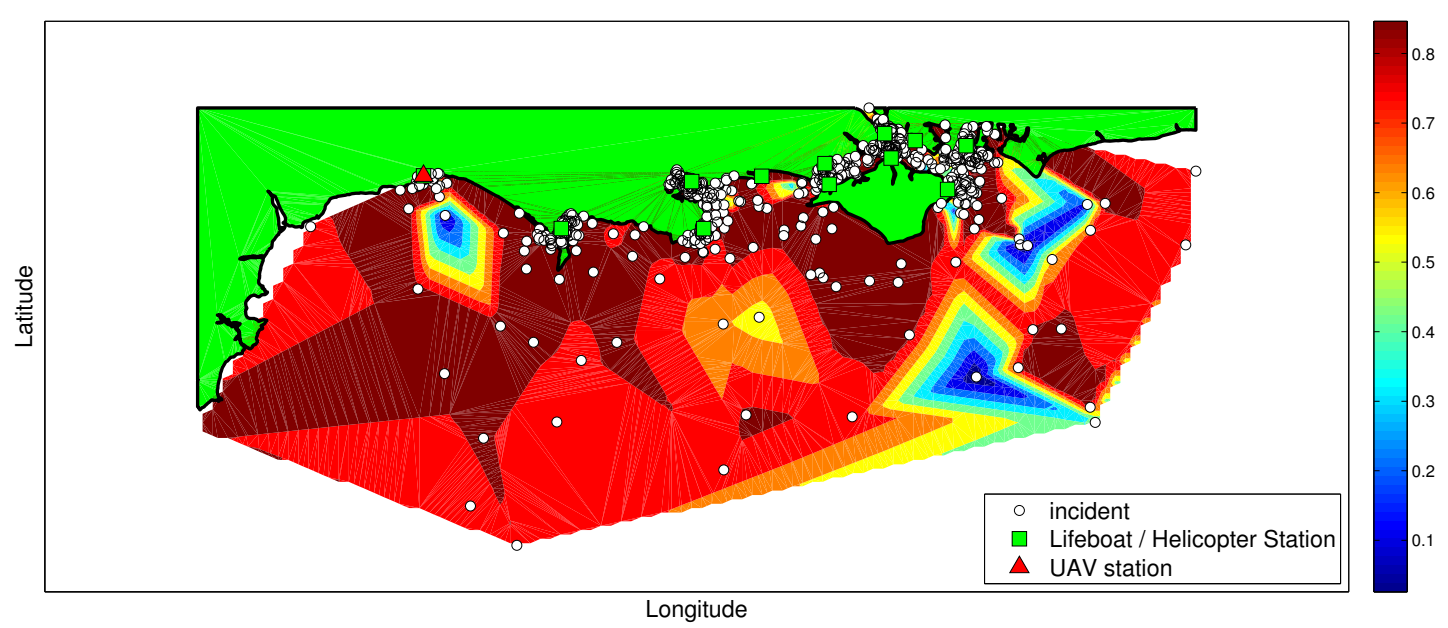

Fig. 9: Probability of survival in the context of a search and rescue mission. Plotted over a section of the South-East coast of the UK for one UAV design (landing speed of 20m/s, $6 \mathrm{~kg}$ payload).

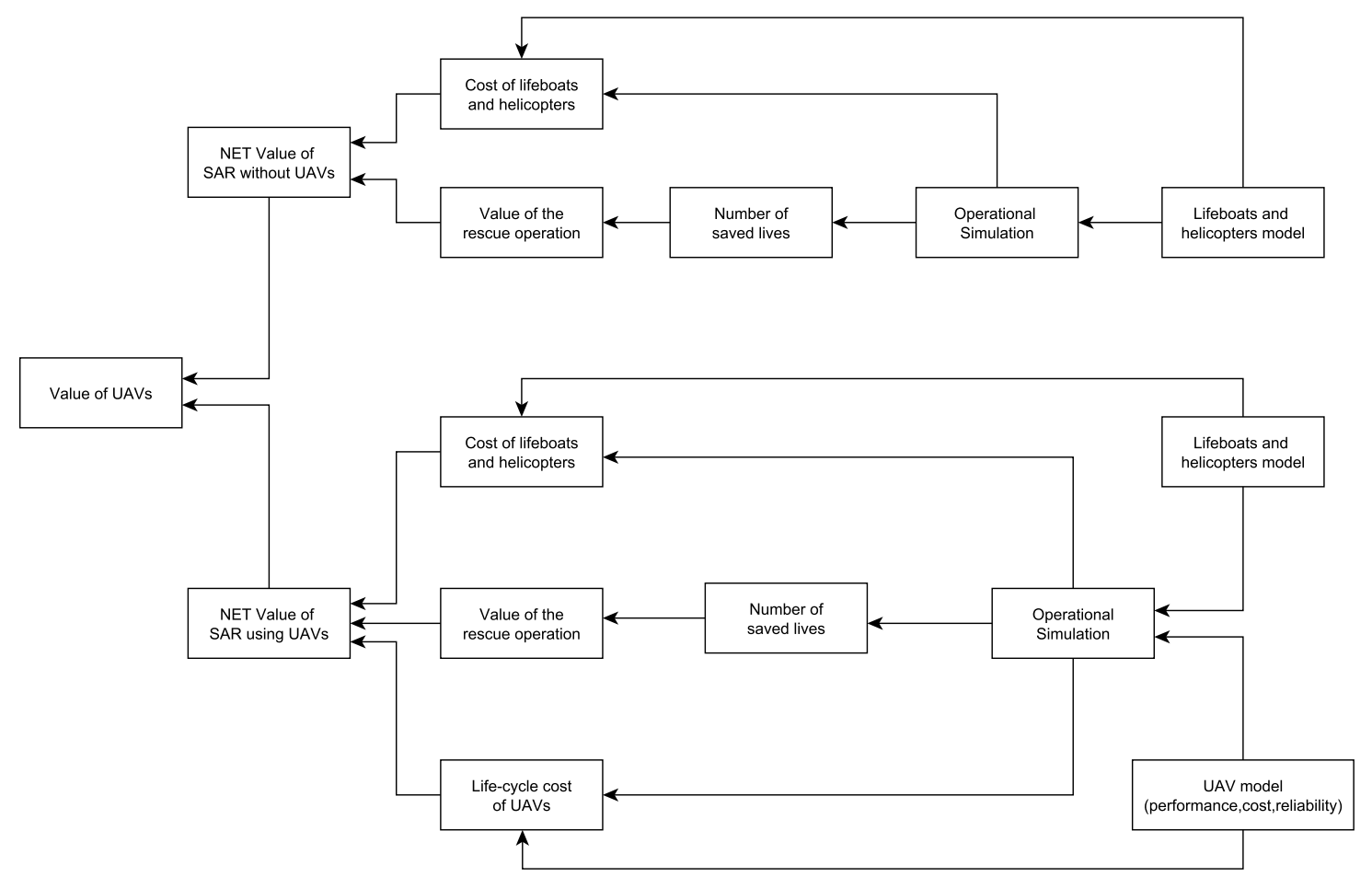

Fig. 10: High level structure of the value model

suggests that a small increase in the number of saved lives generates a very large increment in the value metric against a relatively small increment in the operative costs, pushing the design toward a heavy payload, fast landing aircraft. Indeed, the plot of the UAV value basically replicates the plot of the number of saved lives. 
Note that while it is possible to have value functions at the component level ([3] discusses this) this was not done here, only a top level system value model was used to avoid over complicating things. How to best link component performance (what Collopy calls extensive attributes) to value is not always obvious. For example, in a weights component a decrease in mass could be made to correspond to an increase in value. On the other hand, a decrease of mass (if in the tail) can be detrimental for the aircraft centre of gravity and should be reflected by a very poor value.

However, it should be noted that the value model is still under development and many of the operational and life-cycle costs associated with the system are not yet fully captured. As the model improves it will lead to a different optimal balance between cost, performance and value of the aircraft. Hence the value model is not treated in detail here.

\section{Comparing configurations}

Once a working aircraft performance and mission model are in place, it becomes straightforward to compare the impact of design constraints and configuration choice.

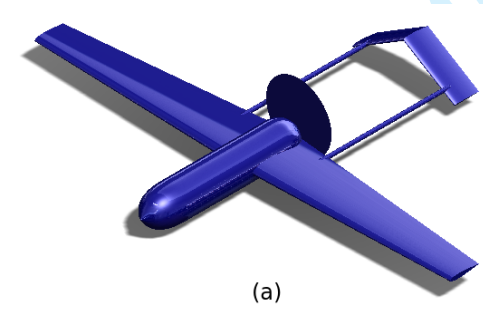

(a)

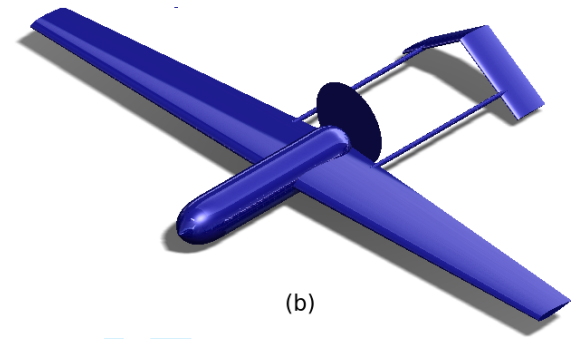

(b)

Fig. 11: The geometry designed by the system for two different runway lengths: $65 \mathrm{~m}$ (a) and $45 \mathrm{~m}$

(b).

Fig. 11 illustrates how the geometry changes for two different scenarios using the same configuration. The figure shows the impact of take-off distance on the geometry of the aircraft. The engine, propeller and payload are the same for both the aircraft while the maximum take-off distance is set to $65 \mathrm{~m}$ for aircraft (a) and $45 \mathrm{~m}$ for aircraft (b). The figure shows the system has designed the aircraft (b) to have a noticeably higher wing area, slightly higher aspect ratio and smaller tail volume. This corresponds with our intuition: a larger wing area is needed order to achieve a lower take-off speed, but larger wings increase the airframe weight and gust loads. This leads to an overall 
growth of the structural weight and ultimately to a further increase of the wing area.

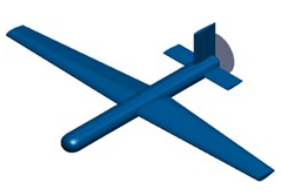

(a) Conventional

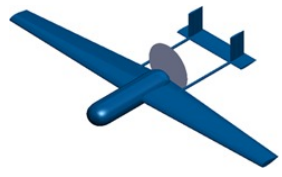

(b) Twin booms

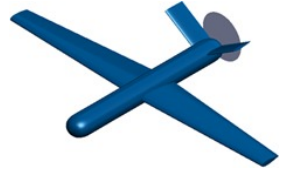

(c) V-tail

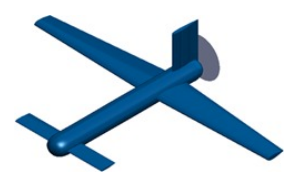

(d) Canard

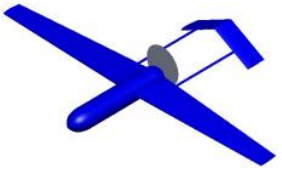

(e) Twin boom inverted-V

Fig. 12: The configurations compared

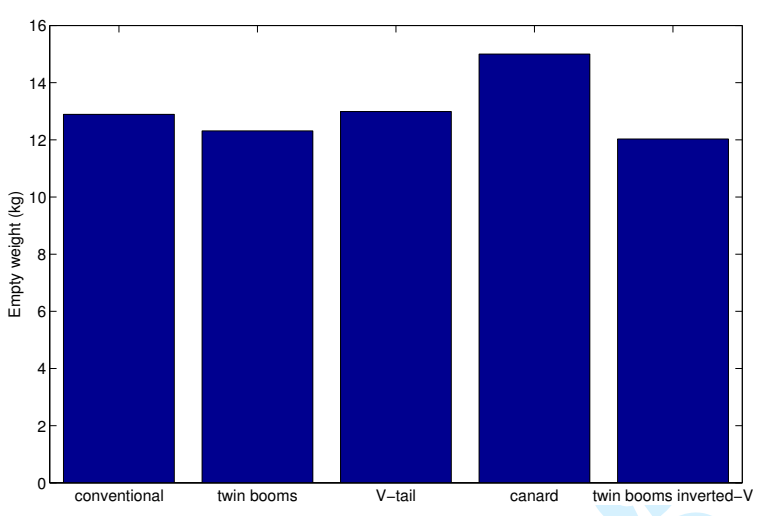

(a) Empty weight

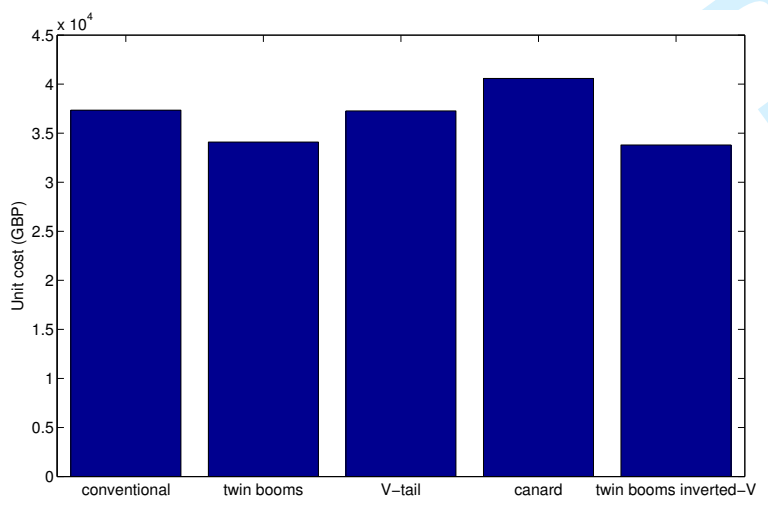

(c) Unit build cost

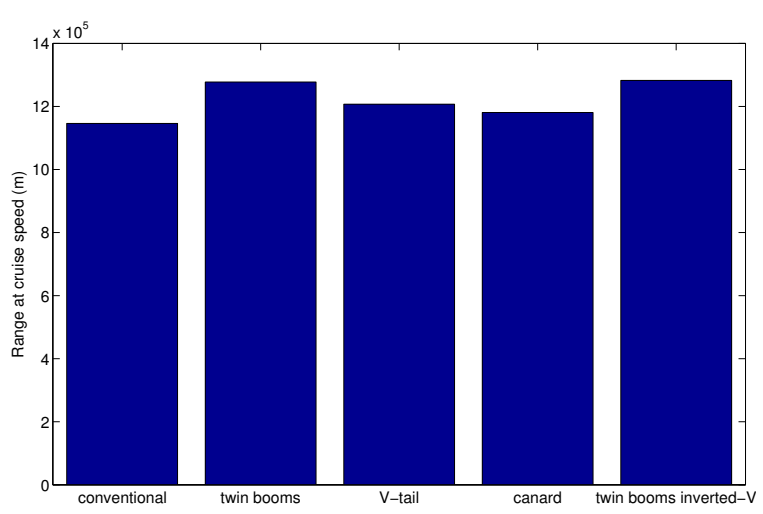

(b) Range at cruise speed

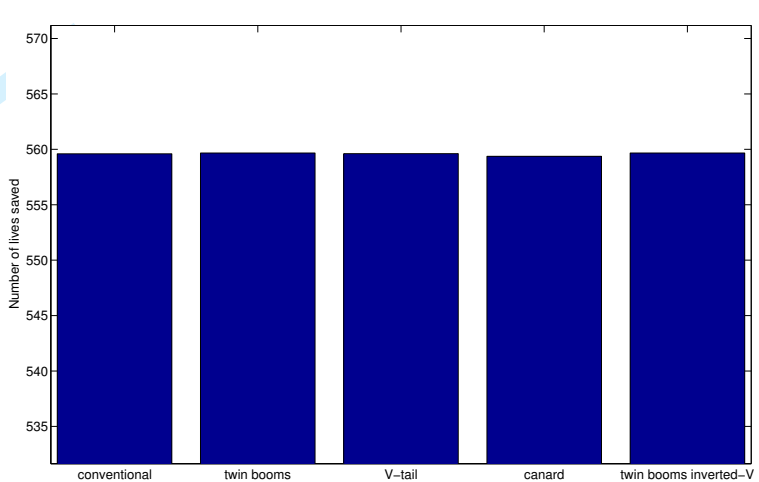

(d) Number of saved lives

Fig. 13: Comparing different aircraft configurations.

Fig. 13 then shows how five different configurations (shown in Fig. 12) compare in terms of weight, range, unit cost, and mission performance. These plots are obtained for a payload weight of $5 \mathrm{~kg}$ and a landing speed of $18 \mathrm{~m} / \mathrm{s}$. For each configuration, the aircraft sizing tool optimizes the design in order to maximize an objective function which is a linear function of range, dash and 
landing performance. At the same time it ensures that all the design constraints are satisfied.

Figure 13a and 13c highlight that the twin-boom configurations $12 \mathrm{~b}$ and $12 \mathrm{e}$ result in lighter and less expensive aircrafts than the conventional configurations 12a and 12c. Twin boom configurations also result in a longer range (Fig. 13b). V-tail empennages provide better performance than conventional rudder plus elevator configurations for both the conventional and twin-boom aircrafts. The canard configuration $12 \mathrm{~d}$ is heavier and more expensive than the other configurations and ranks second last for range. Figure 13d shows how the different configurations perform in the search and rescue mission. Since the payload is the same for all the configurations and the accidents locations are generally within the maximum range of the UAVs, the average number of saved lives is mainly influenced by the dash speed of the aircraft. As mentioned above, the impact of this is very small due to the locality of the incidents, explaining the close values.

Given the plots in Fig. 13 a designer would expect the twin-boom inverted V-tail configuration to be the best for the given mission: the life-cycle cost is likely to be lower because the airframe is less expensive (Fig. 13c) and the fuel consumption is lower (hence more range in Fig. 13b) than the other configurations. At the same time the probability of landing mishaps is lower given the lower structural weight and the expected number of saved life is higher as well. In this case the value model, where cost and performance data is fed into, confirmns this intuition.

Note that a value-driven approach does not make plots such as those in Fig. 13 obsolete. Although the value metric on its own should in theory be sufficient to establish the best aircraft for the given mission, we recognize that the decision makers should be presented with enough information to properly understand the design trade-offs. The final outcome of the value model is the result of a complex computation that takes into account cost, performance and reliability of an aircraft. In order to maintain understanding and build trust in the value model such background results should still be readily accessible and the whole tightly integrated with the design rationale.

\section{UAVs built}

An important goal of the DECODE project was not to limit the scope to the computational domain but to go through the complete process of manufacturing and testing the designs. The first 
version of the system was bootstrapped with the design of a $10 \mathrm{~kg}$, twin tailboom, pusher UAV

(Fig. 14). It was rapid prototyped in ABS and nylon with carbon fibre and fiberglass clad foam. It is powered with a four stroke glow fuel engine and equipped with a Sky Circuits ${ }^{\mathrm{TM}}$ [50] autopilot.

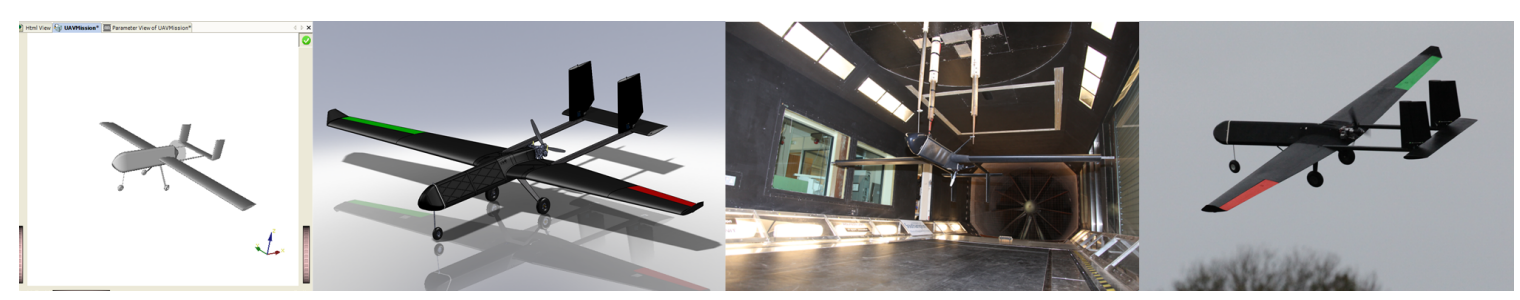

Fig. 14: The DECODE Mark I airframe in concept design, detailed design, windtunnel testing, and during flight testing.

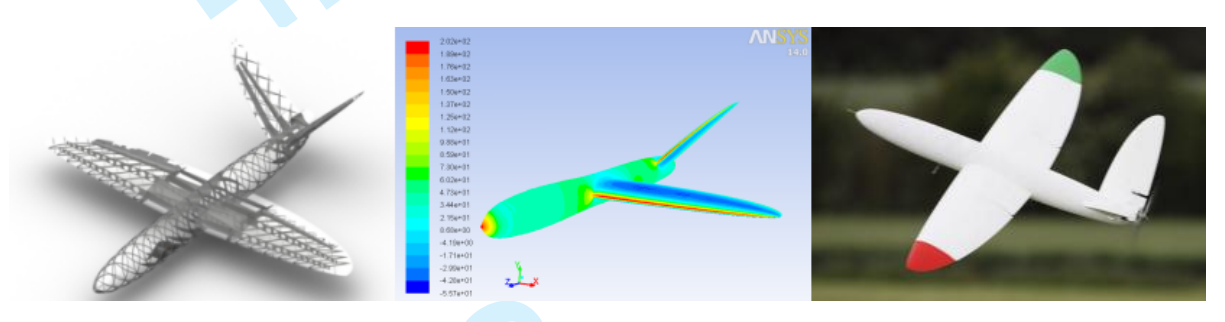

Fig. 15: The SULSA airframe in detailed design, CFD, and during flight testing. The worlds first fully $3 \mathrm{D}$ printed aircraft, printed in just four separate pieces and fully assembled in less than 10 minutes without any screws, clips or fasteners.

The system was further improved with the design and manufacture of a second, much smaller airframe (3 kg take-off weight). It was codenamed SULSA (Fig. 15), electric powered, generated from a parametric geometry model and entirely printed using laser sintering (it was the worlds first fully $3 \mathrm{D}$ printed aircraft). This allowed for complex design features such as elliptical wings and geodetic fuselage reinforcements without adding to the manufacturing cost.

While still mainly a manual process, relying heavily on conventional tools and engineering experience both airframes (and others built by students) allowed us to get a deeper understanding of the difficulties and tooling requirements needed to deliver on the DECODE vision.

Drawing from these experiences a new, much improved, version of the system has been developed that has been used to guide the configuration and design of our third airframe (Fig. 16), a 20kg (dry weight) twin boom, inverted V-tail, pusher UAV with a petrol engine. 


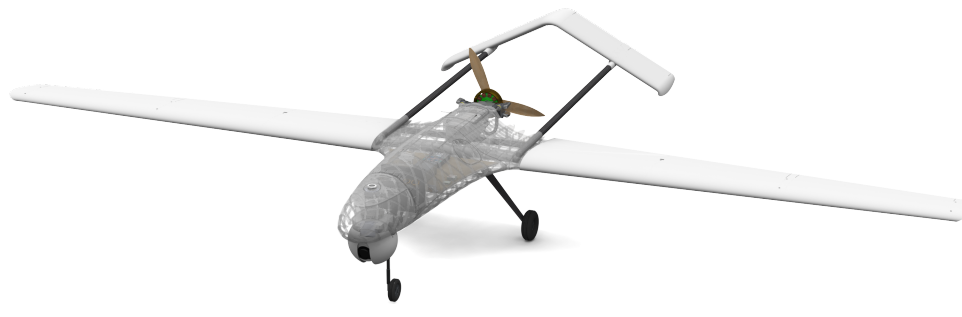

(a) Complete geometry

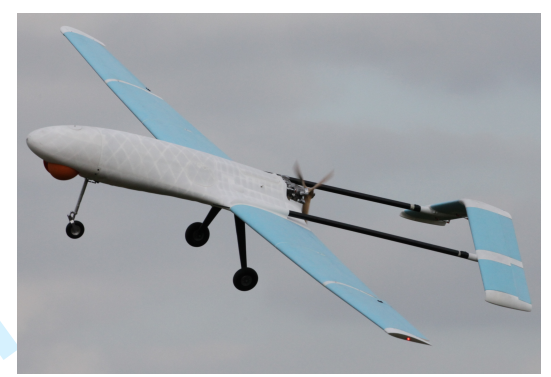

(c) Airframe during first test flight

Fig. 16: The DECODE Mark II airframe

VII. Conclusion and future work

The aim of DECODE is to conduct research at the Value Driven Design level in a highly realistic setting where real aircraft are designed, built and flown. The goal is to demonstrate a capability that allows organizations to analyze, search for and understand the optimum trade-offs between capability, cost and life for a complex system. To this end a software system has been implemented that acts as a decision support tool and orchestrates the different modules (aerodynamics, structures, mission simulation, etc.) in a distributed, loosely coupled manner with good scalability characteristics. As part of realizing the vision two UAV airframes have been designed and flown successfully, with a third airframe currently in design. This has enabled a feedback loop not possible through a purely computational approach.

Current and future work will focus on improving the individual modules. In particular the operational simulation and value model continue to be worked on as they are key to the whole decision making process. A large part of this is performing many trade studies and ensuring all trends and features can be plausibly explained. Work is also underway to broaden the scope of the mission simulation to support a more diverse set of easily programmable missions. One class of 
questions the authors are particularly interested in answering is on the fleet mix level. For example, can more lives be saved by deploying many small, cheap UAVs or a few expensive high performance and highly reliable UAVs?

On the design side the authors are investigating integrating the open source OpenMDAO tool and using it as a pluggable basis to add new multidisciplinary design optimization algorithms (building on our work in [51]) as well as evaluating the usefulness of its EGADS geometry component [52] or the recently released OpenVSP. Another focus area will be the addition of a surrogate modeling layer that provides a middle ground between the high and low fidelity solvers and can act as a buffer in optimization scenarios.

The system is also starting to be deployed to students as part of their curriculum. This will give us more feedback as to where the system is more or less useful and where there is room for improvement. This will lead to further improvements, features, and supported configurations in the system clients (particularly the web client) and a tighter integration of rationale data.

\section{Acknowledgements}

The authors would like to acknowledge the EPSRC for funding the DECODE project, the use of the SPITFIRE and IRIDIS High Performance Computing Facilities at University of Southampton and ANSYS software, including the associated support services, for producing the analysed results.

\section{References}

[1] Ruffles, P., "Improving the new product introduction process in manufacturing companies," International Journal of Manufacturing Technology and Management , Vol. 1, 2000, pp. 1-19.

[2] Johnson, C. L. and Smith, M., Kelly: More Than My Share of It All, Smithsonian Institution Press, 1985.

[3] Collopy, P. D. and Hollingsworth, P. M., "Value-Driven Design," JOURNAL OF AIRCRAFT , Vol. 48, No. 3, 2011, pp. 749-759.

[4] Ross, A. M., O’Neil, G. M., Hastings, D. E., and Rhodes, D. H., “Aligning Perspectives and Methods for Value-Driven Design," AIAA SPACE 2010 Conference $\&$ Exposition, No. September, Anaheim, California, 2010 . 
[5] Dahlgren, J. W., "Real Options and Value Driven Design in Spiral Development," Proceedings of the INCOSE International Symposium, Orlando, FL , 2006.

[6] Ahmed, S., Blessing, L. T. M., and Wallace, K. M., "The relationship between data, information and knowledge based on a preliminary study of engineering designers," ASME Design Engineering Technical Conferences and Computers in Engineering Conference (DETC'99) , 1999.

[7] Hansen, C. T. and Ahmed, S., "An analysis of design decision-making in industrial practice," The "th International Design Conference, May 2002, pp. 145-150.

[8] Price, M., Raghunathan, S., and Curran, R., "An integrated systems engineering approach to aircraft design," Progress in Aerospace Sciences, Vol. 42, No. 4, June 2006, pp. 331-376.

[9] Keane, A. J. and Nair, P. B., Computational approaches for Aerospace Design, The Pursuit of Excellence, John Wiley \& Sons Ltd., The Atrium, Southern Gate, Chichester, West Sussex PO19 8SQ, England, 2005.

[10] Eres, M. H., Pound, G. E., Jiao, Z., Wason, J. L., Xu, F., Keane, A. J., and Cox, S. J., "Implementation and utilisation of a Grid-enabled problem solving environment in Matlab." Future Generation Comp. Syst., Vol. 21, No. 6, 2005, pp. 920-929.

[11] Kim, J.-H., Lee, H.-J., Kim, S.-H., and Lee, J.-O., “A Problem Solving Environment Portal for Multidisciplinary Design Optimization," Advances in Engineering Software, Vol. 40, No. 8, Aug. 2009, pp. 623-629.

[12] Agte, J., Weck, O., Sobieszczanski-Sobieski, J., Arendsen, P., Morris, A., and Spieck, M., "MDO: assessment and direction for advancement - an opinion of one international group," Structural and Multidisciplinary Optimization, Vol. 40, No. 1-6, 2010, pp. 17-33.

[13] Alfaris, A., Siddiqi, A., Rizk, C., de Weck, O., and Svetinovic, D., "Hierarchical Decomposition and Multidomain Formulation for the Design of Complex Sustainable Systems," Journal of Mechanical Design, Vol. 132, No. 9, 2010, pp. 091003.

[14] Haberfellner, R. and de Weck, O. L., "Agile SYSTEMS ENGINEERING versus engineering AGILE SYSTEMS," Systems Engineering Symposium INCOSE 2005, Rochester, NY , July 2005.

[15] Chiu, P. W., Naim, A. M., Lewis, K. E., and Bloebaum, C. L., "The hyper-radial visualisation method for multi-attribute decision-making under uncertainty," International Journal of Product Development , Vol. 9, No. 1/2/3, 2009.

[16] Stump, G., Lego, S., Yukish, M., Simpson, T. W., and Donndelinger, J. A., "Visual Steering Commands for Trade Space Exploration: User-Guided Sampling With Example," Journal of Computing and Information Science in Engineering , Vol. 9, No. 4, 2009, pp. 44501. 
[17] Morino, L. and Bernardini, G., "Multi-disciplinary optimization for the conceptual design of innovative aircraft configurations," Computer Modeling in Engineering and Sciences , Vol. 13, No. 1, 2006, pp. 1-18.

[18] Piperni, P., Abdo, M., Kafyeke, F., and Isikveren, A. T., "Preliminary Aerostructural Optimization of a Large Business Jet," Journal of Aircraft, Vol. 44, No. 5, Sept. 2007, pp. 1422-1438.

[19] Krus, P., "Whole Aircraft Simulation for System Design and Optimsation in Preliminary Design," 3rd CEAS AirßSpace Conference, 21st AIDAA Congress, 2011.

[20] La Rocca, G. and Van Tooren, M. J. L., "Knowledge-Based Engineering Approach to Support Aircraft Multidisciplinary Design and Optimization," Journal of Aircraft, Vol. 46, No. 6, Nov. 2009, pp. 18751885.

[21] Werner-Westphal, C., Heinze, W., and Horst, P., "Multidisciplinary Integrated Preliminary Design Applied to Unconventional Aircraft Configurations," Journal of Aircraft, Vol. 45, No. 2, March 2008, pp. 581-590.

[22] Amadori, K. and Johansson, B., "Using CAD Tools and Aerodynamic Codes in a Distributed Conceptual Design Framework," 45th AIAA Aerospace Sciences Conference , 2007, pp. 1-11.

[23] Dufresne, S., Johnson, C., and Mavris, D. N., "Variable Fidelity Conceptual Design Environment for Revolutionary Unmanned Aerial Vehicles," Journal of Aircraft, Vol. 45, No. 4, 2008, pp. 1405-1418.

[24] Rajagopal, S. and Ganguli, R., "Conceptual design of UAV using Kriging based multi-objective genetic algorithm," Aeronautical Journal, Vol. 112, No. 1137, 2008, pp. 653-662.

[25] Iqbal, L. U. and Sullivan, J. P., "Balanced Approach to the Aircraft Design," 50th AIAA Aerospace Sciences Meeting, Nashville, Tennessee, 2012.

[26] Hwang, H., Jung, K., Kang, I., Kim, M., Park, S., and Kim, J., "Multidisciplinary aircraft design and evaluation software integrating CAD, analysis, database, and optimization," Advances in Engineering Software, Vol. 37, No. 5, May 2006, pp. 312-326.

[27] Gray, J., Moore, K. T., and Naylor, B. A., "OpenMDAO: An Open Source Framework for Multidisciplinary Analysis and Optimization," AIAA Journal, No. September, AIAA, 2010.

[28] Hahn, A. and Langley, N., "Vehicle Sketch Pad : A Parametric Geometry Modeler for Conceptual Aircraft Design," 48th AIAA Aerospace Sciences Meeting , No. January, Orlando, FL, 2010.

[29] Tomac, M. and Eller, D., "From geometry to CFD grids - An automated approach for conceptual design," Progress in Aerospace Sciences, Vol. 47, No. 8, Nov. 2011, pp. 589-596.

[30] Rizzi, A., Zhang, M., Nagel, B., Boehnke, D., and Saquet, P., "Towards a Unified Framework using CPACS for Geometry Management in Aircraft Design," 50th AIAA Aerospace Sciences Meeting , Nashville, Tennessee, 2012. 
[31] Collopy, P., "Economic-Based Distributed Optimal Design," Tech. rep., American Institute of Aeronautics and Astronautics, Reston, VA, 2001.

[32] ONeill, M. G., Yue, H., Nag, S., Grogan, P., and de Weck, O., "Comparing and Optimizing the DARPA System F6 Program Value-Centric Design Methodologies," AIAA SPACE 2010 Conference 63 Exposition, Anaheim, CA, 2010.

[33] AIAA Value-Driven Design Committee, "https://info.aiaa.org/tac/pc/VDDPC/default.aspx," .

[34] Schumann, B., Scanlan, J., and Takeda, K., "A Generic Operational Simulation for Early Design Civil Unmanned Aerial Vehicles," SIMUL 2011, The Third International Conference on Advances in System Simulation, No. VDD, 2011, pp. 67-70.

[35] Schumann, B., Scanlan, J., Fangohr, H., and Ferraro, M., "A Generic Unifying Ontology for Civil Unmanned Aerial Vehicle Missions," Aviation Technology, Integration, and Operations (ATIO) Conferences, American Institute of Aeronautics and Astronautics, Indianapolis, Indiana, USA, Sept. 2012.

[36] Ferraro, M., Gorissen, D., Scanlan, J., Keane, A. J., Takeda, K., Quaranata, E., Schumann, B., Van Schaik, J., and Bolinches, M., "Value-Driven Design of a small, low-cost UAV," 53rd AIAA/ASME/ASCE/AHS/ASC Structures, Structural Dynamics and Materials Conference , Vol. 1, Honolulu, Hawaii, 2012.

[37] Bolinches, M., Keane, A., Forrester, A., Scanlan, J., and Takeda, K., "Design, analysis and experimental validation of a morphing UAV wing," The Aeronatical Journal , Vol. 115, No. 1174, 2011, pp. 761-756.

[38] Raymer, D., Aircraft Design: A Conceptual Approach , Vol. 4 of AIAA Educational Series, AIAA, 2006.

[39] Torenbeek, E., Synthesis of Subsonic Airplane Design: An Introduction to the Preliminary Design of Subsonic General Aviation and Transport Aircraft, with Emphasis on ... Design, Propulsion and Performance, Springer, 1982.

[40] Gibey, R., "Computer program for estimation of aerofoil characteristics at subcritical speeds: lift-curve slope, zero-lift incidence and pitching moment, aerodynamic centre and drag polar minimum," Tech. rep., ESDU, 2006.

[41] Schumann, B., Scanlan, J., and Takeda, K., "Evaluating design decisions in real-time using operations modelling," 2nd International Air Transport and Operations Symposium, Delft , 2011, pp. 383-392.

[42] Cheung, J. M. W., Scanlan, J. P., and Wiseall, S. S., "An aerospace component cost modelling study for value driven design," CIRP IPS2 Conference 2009: Industrial Product-Service Systems , 2009.

[43] Scanlan, J., Thokala, P., and Chipperfield, A., "Life cycle cost modelling as an aircraft design support tool," Proceedings of the Proceedings of the Institution of Mechanical Engineers, Part G: Journal of Aerospace Engineering, Vol. (in press), 2009. 
[44] Moran, T. P. and Carroll, J. M., Design rationale: concepts, techniques, and use , L. Erlbaum Associates Inc., Hillsdale, NJ, USA, 1996.

[45] Emberey, C. L., Milton, N. R., Berends, J., Tooren, M. V., Elst, S. V. D., and Vermeulen, B., "Application of Knowledge Engineering Methodologies to Support Engineering Design Application Development in Aerospace," Proceedings of the 7th AIAA Aviation Technology, Integration and Operations Conference (ATIO), AIAA-2007-7708, Belfast, Ireland , 2007.

[46] McMahon, C., Lowe, A., and Culley, S., "Knowledge management in engineering design: personalization and codification," Journal of Engineering Design, Vol. 15, No. 19, 2004, pp. 307-325.

[47] Van Schaik, J., Scanlan, J., Keane, A. J., and Gorissen, D., "Improving design rationale capture during embodiment design," International Conference on Engineering Design (ICED11) , No. August, Technical University of Denmark, 2011, pp. 436-445.

[48] Buckingham Shum, S. J., Selvin, A. M., Sierhuis, M., Conklin, J., Haley, C. B., and Nuseibeh, B., In Rationale Management in Software Engineering , Vol. 4, chap. Hypermedia, Springer, 2006, pp. 111-132.

[49] Aldy, J. E. and Viscusi, W. K., "The value of a statistical life: A critical review of market estimates throughout the world," Journal of Risk and uncertainty , Vol. 27, No. 1, 2003, pp. 5-76.

[50] Sky Circuits, "http://www.skycircuits.com,"

[51] Price, A. R., Keane, A. J., and Holden, C. M. E., "On the Coordination of Multidisciplinary Design Optimization Using Expert Systems," AIAA Journal, Vol. 49, No. 8, 2011, pp. 1778-1807.

[52] Haimes, R. and Drela, M., "On The Construction of Aircraft Conceptual Geometry for High-Fidelity Analysis and Design," 50th AIAA Aerospace Sciences Meeting, Nashville, Tennessee, 2012. 